\title{
Design and development of three stages maximum power tracking solar charge controller
}

\author{
N.H. Abdul Rahman ${ }^{1}$, A.M. Omar' ${ }^{2}$, E.H. Mat Saat ${ }^{3}$, N.I. Ilham ${ }^{4}$, M.Z. Hussin ${ }^{5}$, Yusrina Y ${ }^{6}$ \\ 1,3,4,5,6Fakulti Kejuruteraan Elektrik, UiTM Cawangan Johor Kampus Pasir Gudang, Malaysia \\ ${ }^{2}$ Fakulti Kejuruteraan Elektrik, Universiti Teknologi MARA, Malaysia
}

\begin{tabular}{l} 
Article Info \\
\hline Article history: \\
Received Oct 13, 2019 \\
Revised Dec 15, 2019 \\
Accepted Dec 29, 2019 \\
\hline
\end{tabular}

Keywords:

Buck converter

Charge controller

Stand-alone photovoltaic

maximum power point tracking

\begin{abstract}
This paper presents the design of a Three Stages Maximum Power Point Tracking (MPPT) charge controller for improving the charging/discharging control of the battery. In this research, Buck Converter is used to regulate the voltage from the Photovoltaic (PV) module to the required voltage. This research is limited to Valve Regulated Lead Acid (VRLA) battery for $12 \mathrm{~V}$ system voltage. The charge control algorithm envisages controlling the charging and discharging action in all the three stages of battery charging, bulk, absorption, and float. The idea is to control the battery charging and discharging status until meeting the battery set-point. The set-point is limited to High Voltage Disconnect (HVD), Low Voltage Disconnect (LVD) and Load Voltage Reconnect (LVR) to protect the battery from over-charging and deep-discharging. The results obtained demonstrate the good performance of the charge controller. With the application of the MPPT algorithm in the bulk stage, the time taken to get the battery to fully charged state becomes faster The regulation power from the converter to the inverter has performed well and the switching relay is managed to be controlled.
\end{abstract}

Copyright $@ 2020$ Institute of Advanced Engineering and Science. All rights reserved.

\section{Corresponding Author:}

Noor Hasliza Abdul Rahman,

Department of Electrical and Computer Engineering,

Universiti Teknologi MARA, Cawangan Johor, Kampus Pasir Gudang,

Jalan Purnama, Bandar Seri Alam, 81750 Masai, Johor, Malaysia.

Email: noorhasliza@uitm.edu.my

\section{INTRODUCTION}

Stand-Alone Photovoltaic (SAPV) system consists of PV module which generates DC power when sunlight shines onto it. PV module has a nonlinear voltage-current characteristic and the performance of the $\mathrm{PV}$ subject to change with the weather changes especially solar irradiance and temperature $[1,2]$. The generated DC power from PV module needs to be stored in a battery to back up the system during the night time or inadequate sunlight. The most widely backup batteries used in SAPV system are Valve Regulated Lead Acid battery (VRLA) and Flooded Lead Acid battery. There are also other types of batteries such as nickel-cadmium battery but it is rarely used in the PV system due to high cost and not readily available [3]. When dealing with the battery, the charge controller is required to regulate power from the PV module to the battery. The controller consists of DC/DC converter to convert DC voltage from PV module to an appropriate voltage level needed to charge the battery. Furthermore, the charge controller is needed to improve the efficiency of the system and protect the battery from overcharging and deep discharging. Overcharging and deep discharging of batteries will reduce battery lifetime and gradually damage the batteries $[4,5]$.

The basic function of the charge controller is to charge and monitor the battery voltage level. The earlier version of the charge controller monitors battery voltage by using a mechanical relay. The relay opens the circuit to stop battery charging once the voltage is increased to a certain level and closes the circuit 
once the battery voltage decreases to a certain level. By frequently opening and closing the relay, the on/off type charge controller tends to limit the use of the available solar energy which leads to a lower state of charge (SOC) and increase of load disconnect. Thus, many researchers have studied to improve battery charging control. The improvement of the charge controller may be divided into two types; Pulse Width Modulation (PWM) charge controller and Maximum Power Point Tracking (MPPT) charge controller.

PWM charge controller controls the amount of power by manipulating a duty cycle of PWM. The duty cycle is reduced to slow down the amount of power flowing into the batteries when the battery is fully charged. By using this method, the float level is achieved with less stress on the battery. The sulphuration problem which is normally occurred in the lead-acid battery will cause the loss of battery capacity [6]. PWM pulse charging discourages the development of sulfate in the battery and helps to overcome the resistive barrier on the surface of the grid corrosion of the battery plate. Apart from that, pulse charging recovers the lost capacity due to sulphation by improving the charging acceptance and efficiency [7]. The efficiency of battery charging is referred to as charge acceptance. The earlier version of the charge controller which uses the mechanical relay to on-off the circuit causes the low charge acceptance of the battery [8]. The extensive study and testing by Ajit et.al [9] showed that PWM charge algorithm increased the charge acceptance and maximized energy transfer to the battery.

Battery SOC is the amount of energy left in the battery concerning the nominal rated battery capacity. The maximum level SOC of the battery is $100 \%$ for all types of fully charged battery. To keep the battery in good or healthy condition and maintain the reserve storage capacity, a daily high SOC is needed. However, the earlier version of the charge controller did not maintain the battery SOC at a high level although the load is disconnected. Research done by Shoaib et.al [7] explained that PWM charge controller maintained average battery capacities at $90 \%$ to $95 \%$ compared to the on-off regulated state of charge level which was typically $55 \%$ to $60 \%$. However, solar power generation systems have two major problems. The first is low conversion efficiency. The commercial PV modules are assembled with $13 \%$ to $20 \%$ efficiency depending on the technology [10]. Second is the nonlinear I-V characteristic of PV module. With the nonlinear characteristic which is dependent on temperature and irradiance level, the PV module performance becomes worse [11]. Due to this poor efficiency which is strongly dependent on solar radiation level and operating temperature, PV module to an extract maximum amount of power to charge the battery using maximum power point tracking system.

The latest type of charge controller is MPPT charge controller. It has been established for PV system used in the battery charging algorithm for the regularly cycle battery charging process $[12,13]$. MPPT is an electronic system that allows PV module to produce all the power that PV module is capable of. The MPPT charge controller is able to optimize the input power from PV module and re-adjusts the voltage for the higher current output to charge the battery. MPPT is DC-DC power converter that controls the operating voltage of PV module to enable PV module operating at maximum power. The previous study found that the efficiency of MPPT charge controller is higher compared to the earlier version and PWM charge controller [14-16]. The MPPT charge controller attempts to keep the PV module at the maximum power point without power loss while supplying varying voltage requirements by the battery. The efficiency loss in the earlier version of the charge controller is due to a miss-match between the voltage produced by the PV module and that required to charge the battery. The charge controller incorporating with MPPT allows PV modules to operate at maximum power and deliver as much 30\% more energy from PV module [17-19]. During charging, the MPPT is applied when the battery voltage is below the maximum voltage level. The maximum voltage is defined as battery at float voltage which normally provided by the battery manufacturer.

Other than higher efficiency, the MPPT charge controller also contributes to the fast charging time $[20,21]$. The MPPT searches for maximum current to charge the battery. With the higher current, the time for the battery voltage to achieve the float level is faster [22]. Compared to the earlier version of the charge controller, the longer time is taken for the controller to charge the battery to a fully charged state. It is because the controller does not fully extract the available PV power due to the limitation of available PV energy at the low solar irradiance. The same method is applied by P.Jun et.al [23], the MPPT charging integrates with variable intermittent current charging increases charging speed and raise the battery SOC. The battery accepts the maximum charging at the low battery voltage. The maximum charging continues until the battery voltage reaches the charging threshold. When the battery is fully charged, the duty cycle is reduced to maintain the battery at $100 \%$ state of charge level.

Due to the above-mentioned superiority of MPPT charge controller, this paper presents the development of three stages MPPT charge controller limited to VRLA battery for 12V system voltage to improve the battery charging and discharging. The ability of the charge controller is observed with the achievement of battery charged at three-stages charging method (bulk, absorb and float). The idea is to control the battery charging and discharging status until meeting the battery set-point. The set-point is limited 
to High Voltage Disconnect (HVD), Low Voltage Disconnect (LVD) and Load Voltage Reconnect (LVR). The purpose of the set-point is to protect the battery from overcharging and deep discharging [24-26].

\section{CHARGE CONTROLLER DEVELOPMENT}

The series charge controller works in series between the PV module and battery rather than in parallel as for the shunt controller. While this type of charge controller is commonly used in small PV systems, it is also a practical choice for large systems due to the current limitations of shunt controllers [27]. The electrical design of the series type charge controller is shown in Figure 1. The controller receives the power of $I_{p v}$ and $V_{p v}$, current and voltage respectively from the PV module. This input power is then extracted to maximum power by MPPT technique. The MPPT is executed by Auto-Scaling Variable Step Size (AVSS) algorithm in the MPPT controller [28].

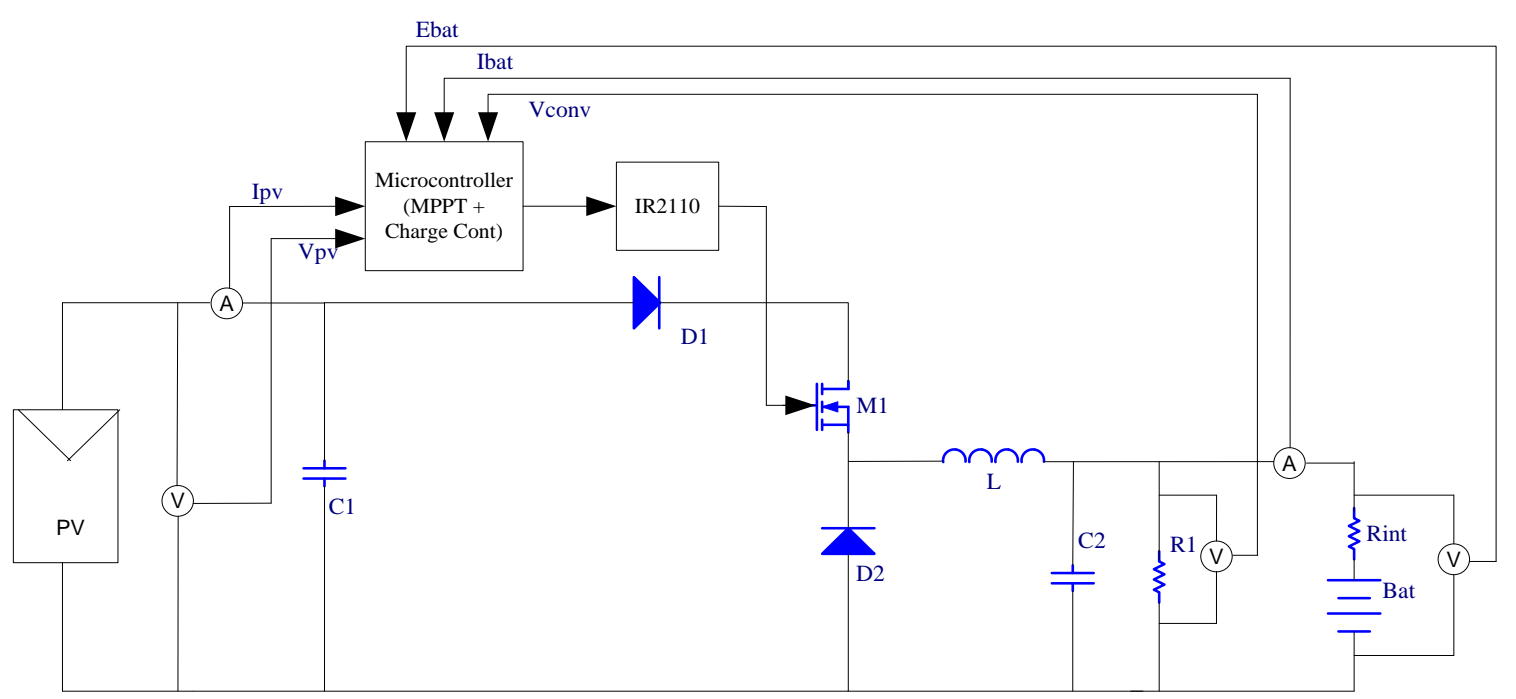

Figure 1. Buck converter circuit diagram characteristic

The maximum PV voltage at which the maximum power is obtained is then converted to the converter voltage, $V_{\text {conv }}$. The $V_{\text {conv }}$ is measured across $R_{l}$ and the battery voltage $E_{b a t}$ is measured across the battery. The value of $R_{l}=12 \mathrm{k} \Omega$ is set to high and battery internal resistance $R_{\text {int }}=1 \Omega$ is set to a small value to allow the power delivered directly to the battery. Figure 2 shows the flowchart of the charge controller operation. Initially, the $V_{c o n v}, I_{b a t}$, and $R_{\text {int }}$ are measured. The operation of the charge controller is controlled by monitoring the value of $E_{b a t}$. The $E_{b a t}$ is obtained by using (1).

$$
E_{b a t}=V_{c o n v}-I_{b a t}\left(R_{\text {int }}\right)
$$

where,

$V_{\text {conv }}$ is the DC converter output voltage [V];

$I_{b a t}$ is the battery charging and discharging current [A];

$R_{\text {int }}$ is the battery internal resistance $[\Omega]$;

The value of $V_{\text {conv }}$ is normally higher than $E_{b a t}$ to ensure the battery is charged properly. The charge controller is constantly monitoring the $E_{b a t}$ and shall limit the current flowing into the battery once the battery reaches $13.5 \mathrm{~V}$. If the $E_{b a t}$ level is higher than $13.5 \mathrm{~V}$, the controller will reduce the duty ratio of PWM to $20 \%$ to avoid battery from overcharging and maintaining the battery voltage at high voltage.

Figure 3 shows the controller set-points of the charge controller. During the discharging mode, the controller disconnects the battery from the load once battery LVD, $11.7 \mathrm{~V}$ is achieved. It is to prevent the battery from deep discharge. The LVD set-point defines the actual allowable maximum depth-of-discharge and available capacity of the battery operating in a PV system. Once the controller disconnects the load from the battery at the LVD set-point, the battery voltage rises to open-circuit voltage during the charging mode. Once an additional charge is provided by the PV array, the battery voltage rises even more. At some point, 
the controller senses that the battery voltage and state of charge are high enough to reconnect the load. LVR is the battery voltage at which a controller allows the load to be reconnected to the battery.

With continuous charging, the battery achieves float voltage at $13.5 \mathrm{~V}$ and this voltage increases if the battery is continuous charging. The float voltage is defined as the maximum voltage that the charge controller allows the battery to reach, limiting the battery overcharge. Once the controller senses that the battery has reached more than float set-point HVD, the controller will limit the current delivered to the battery.

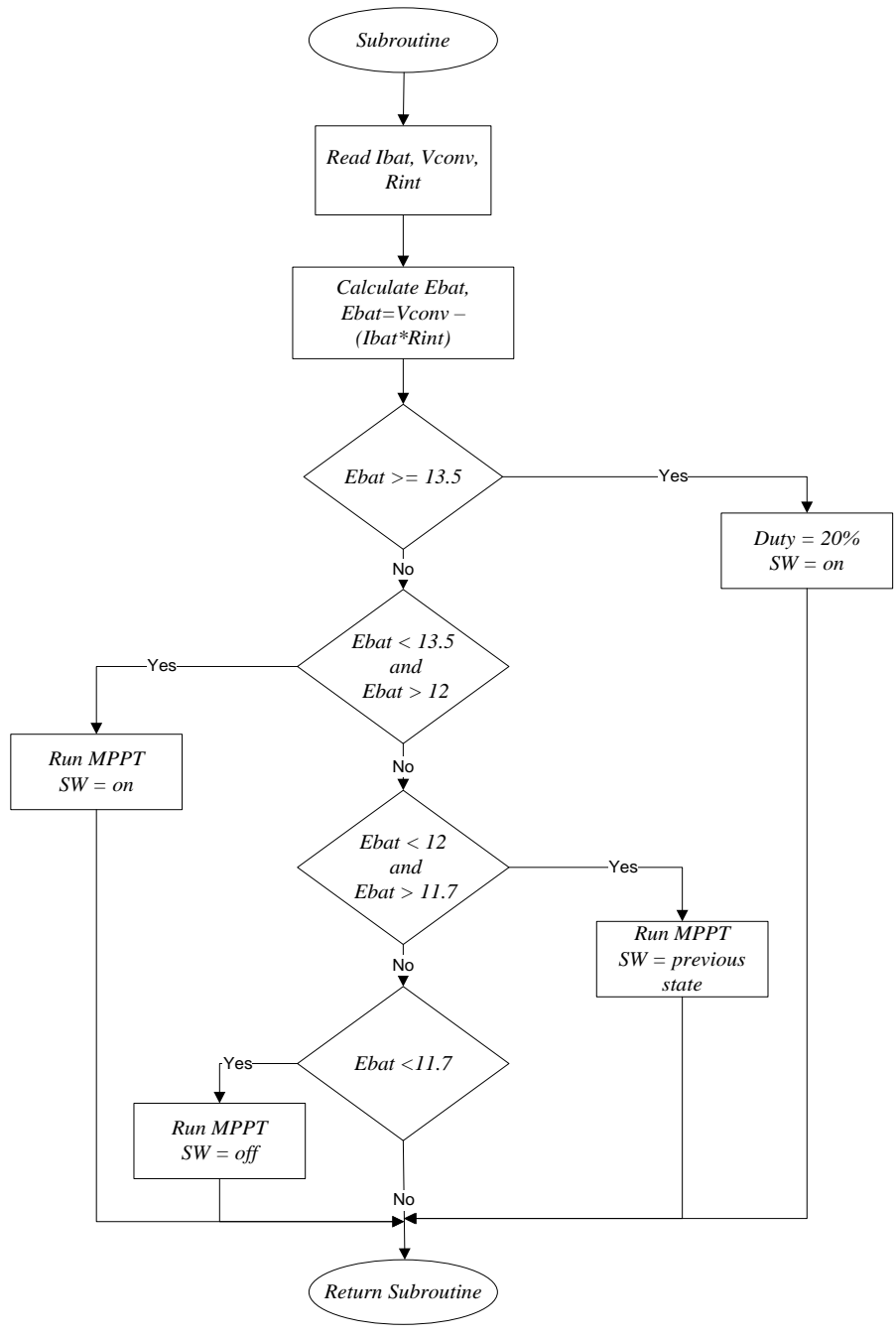

Figure 2. Flowchart of charge controller operation

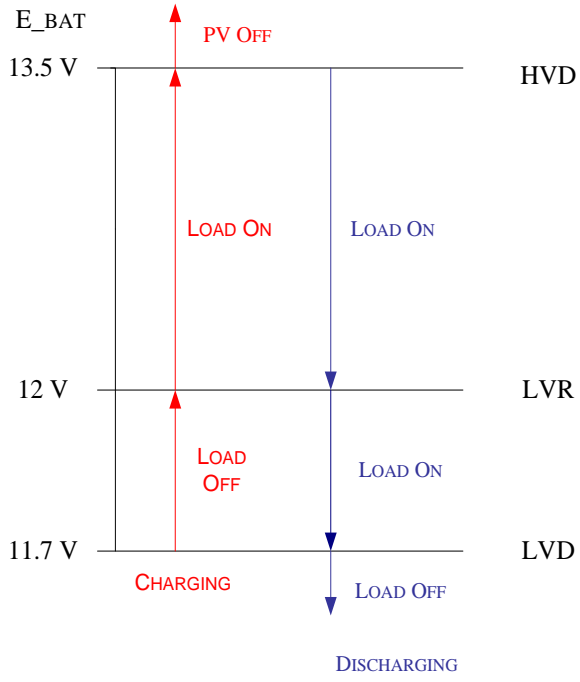

Figure 3. Charge controller set-point

\section{THREE-STAGE BATTERY CHARGING PERFORMANCE}

The developed charge controller is tested with three-stage battery charging. In this charging method, the whole energy from the PV module is delivered to the battery. Figure 4 shows the three-stage of battery charging for $12 \mathrm{~V}, 26 \mathrm{AH}$ MSB VRLA battery. In the first two hours of operation, the battery is in the bulk charging stage. In this stage, the battery is charged at a constant current of $70 \%-80 \%$ of the battery SOC. An Auto-Scaling Variable Step Size (AVSS) MPPT algorithm is applied during a bulk-charging stage. From the result, the battery is charged with an average current, 1.8A. At the constant current charging, the voltage of the battery is increased from $10.5 \mathrm{~V}$ until it reaches constant voltage, $14 \mathrm{~V}$ which is called an absorption stage.

In the absorption stage, the remaining $20 \%-30 \%$ of SOC is replenished. The absorption stage is initiated when the battery voltage reaches constant voltage. The battery voltage remains constant at $14 \mathrm{~V}$ until the battery is fully charged. At the same time, the battery charging current is progressively reduced as internal resistance increases. 
Once the battery is fully charged, the charging voltage is reduced from $14 \mathrm{~V}$ to $13.5 \mathrm{~V}$ to minimize gassing and to prolong battery life. The float-charging stage is initiated when the battery voltage is $13.5 \mathrm{~V}$ as recommended by the battery manufacturer. During the float stage, the current is decreased to $0.5 \mathrm{~A}$. The $0.5 \mathrm{~A}$ remains in the float stage by applying trickle charges. The main purpose of the trickle charges is to prevent the battery from overcharging and at the same time to maintain a high battery voltage level. The battery is completely fully charged in five hours of operation.

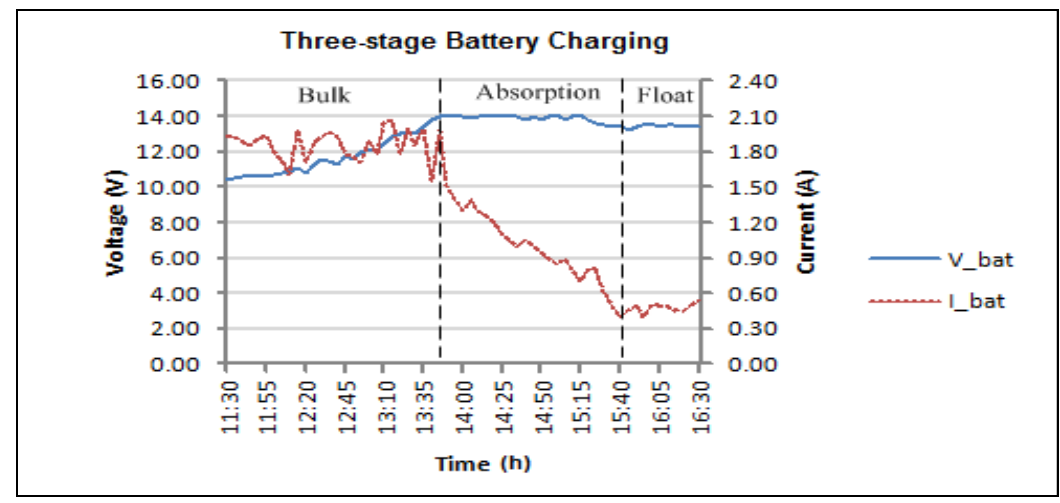

Figure 4. Three-stage battery charging

\section{OVER-CHARGING AND DEEP CHARGING CONTROL}

For the overcharging and deep discharging battery control, the charge controller is set to $13.5 \mathrm{~V}$ as HVD, $12 \mathrm{~V}$ as LVR and $11.7 \mathrm{~V}$ as LVD set-point. The testing is executed with two types of testing. The objective of this testing is to analyze the charge controller performance in a different situation. At the first testing, the controller charges the battery for some considerable time and then discharges. This testing is to test the functionality of the LVD and LVR in the developed integrated system. As for the load, a $30 \mathrm{~W}$ bulb is connected to the integrated system.

At the second testing, the controller charges and discharges the battery simultaneously. During this testing, a $30 \mathrm{~W}$ bulb is changed to a $25 \mathrm{~W}$ bulb to test the functionality of HVD. The changes in charging and discharging mode of the battery are affected by the battery level voltage, $E_{b a t}$. Figure 5 presents the result of the LVD and LVR test for 6 hours of operation. The irradiance level is presented in Figure 5(a). During the first 3 hours of operation (10:00 to 13:00), the system is operated with a high irradiance level at $700 \mathrm{~W} / \mathrm{m}^{2}$. However, there are fluctuations in irradiance between $700 \mathrm{~W} / \mathrm{m}^{2}$ and $400 \mathrm{~W} / \mathrm{m}^{2}$. The changing of irradiance level affects the $P_{m p}$ as shown in Figure 5(b). The generated maximum power corresponds to the change in irradiance are between $16 \mathrm{~W}$ to $27 \mathrm{~W}$. During this time, the battery voltage, $E_{\text {bat }}$ is calculated below than LVD set-point $(11.7 \mathrm{~V})$. When the LVD set-point is detected, the load is cut off from the system $(\mathrm{SW}=0)$. As shown in Figure 5(c), when the load is disconnected from the system, the battery is charged by the $I_{p v}$. The positive sign of $I_{b a t}$ indicates that the battery is in charging mode. From the result, it is observed that the values of $I_{p v}$ and $I_{b a t}$ are at the same level which indicates that the battery is charged with the same amount of current delivered from the PV module. With the constant charging current, the $E_{b a t}$ will increase until it reaches the LVR set-point (12V).

At 13:00, the irradiance level decreases to $100 \mathrm{~W} / \mathrm{m}^{2}$ and below due to raining. During this time, the $I_{p v}=0$ thus there is no current flowing into the battery. Since the $E_{b a t}$ has achieved the LVR set-point, the load is reconnected to the system by switching on the relay $(\mathrm{SW}=5 \mathrm{~V})$. At this time, the battery supplies $0.35 \mathrm{~A}$ current to power the load. The negative sign of $I_{b a t}$ indicates the battery is in the discharging mode.

The result of HVD test is presented in Figure 6. For this testing, the load is changed to a $25 \mathrm{~W}$ bulb. Due to the low load, the PV power supply is sufficient to charge the battery at the same time power is supplied to the load. Initially, the PV module is supplied with 1.8A-2A of current to the system. At the same time, $I_{b a t}$ receives the charging current from the PV module with a small value which depends on the battery requirement. Since the system recognizes the $E_{b a t}$ that is above the LVD set-point, the relay is then switched on. The power from the PV module and battery is supplied to the load. The PV module continuously charges the battery until $E_{b a t}$ reaches the float voltage. The float voltage is reached at 12:40. During this time, the controller cuts off power demand from PV module to the battery since the $E_{b a t}$ has exceeded the HVD setpoint $(13.5 \mathrm{~V})$. Thus, the duty cycle has reduced to $20 \%$ to minimize charging current from PV module and at the same time maintained the battery voltage at a high level. 


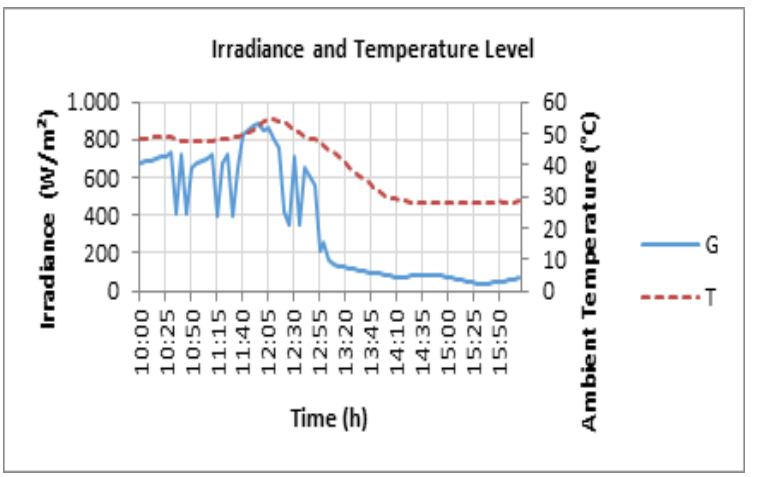

(a)

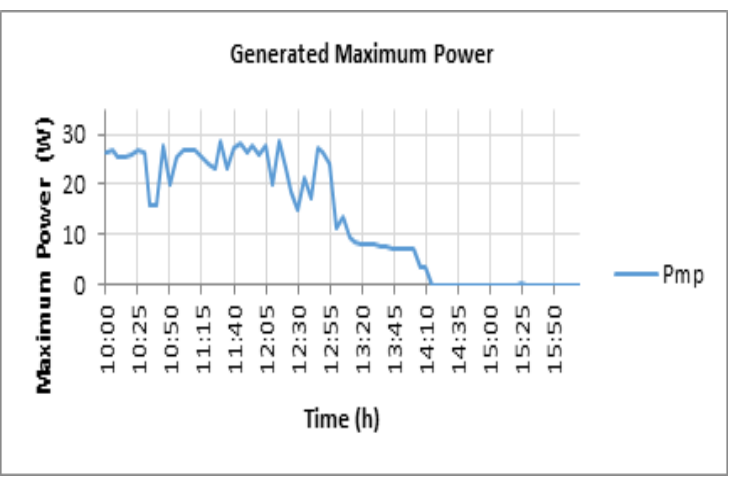

(b)

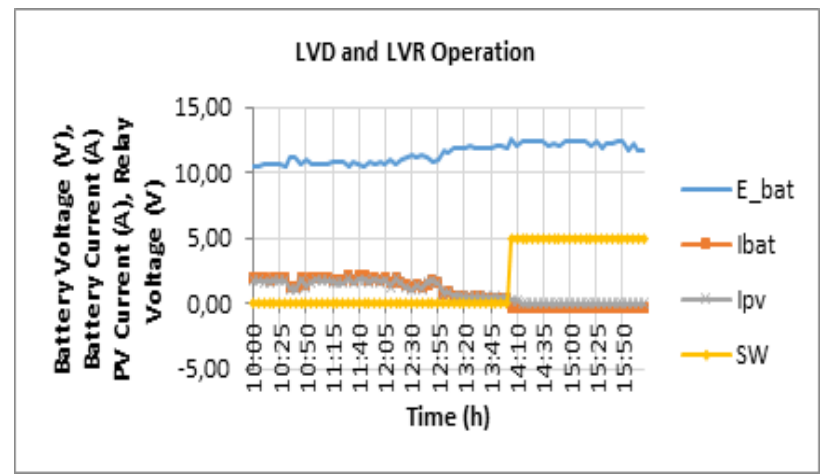

(c)

Figure 5. LVR and LVD functionality test

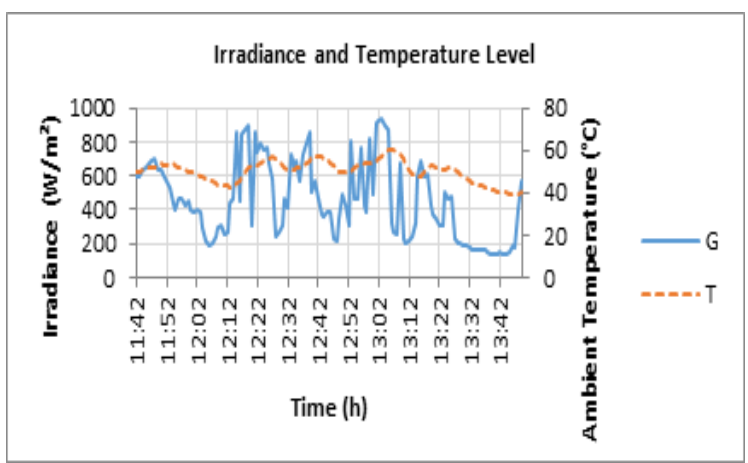

(a)

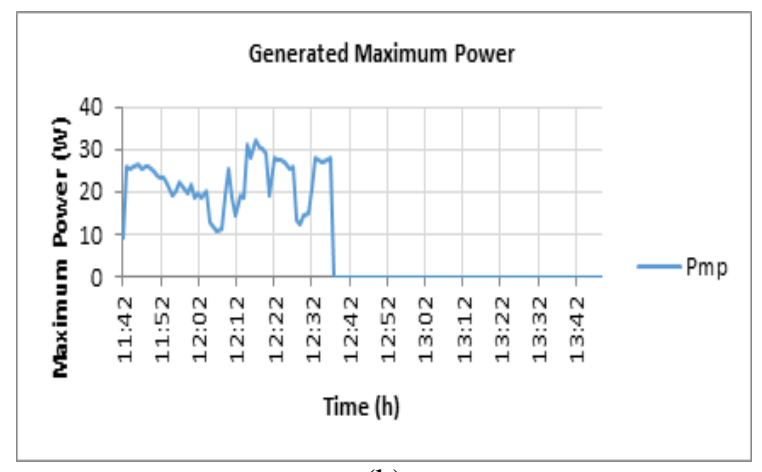

(b)

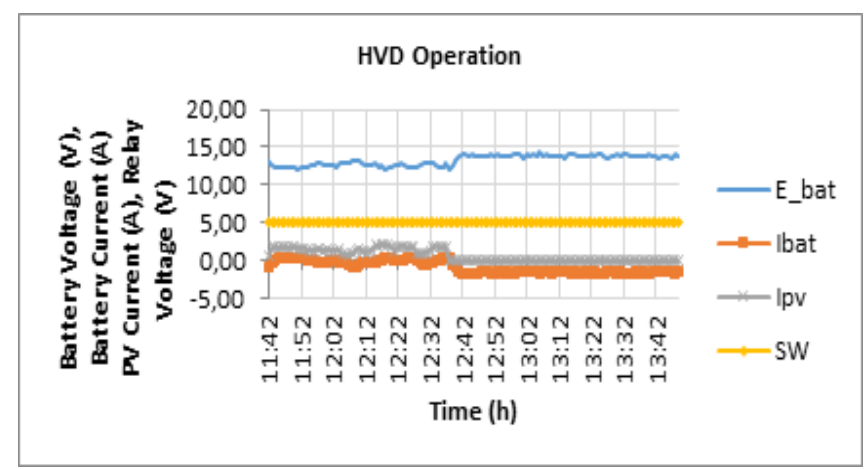

(c)

Figure 6. HVD functionality test 


\section{CONCLUSION}

The developed MPPT charge controller which uses three-stage battery charging, bulk, absorption, and float is able to charge the battery until fully charged. With the application of an Auto-Scaling Variable Step Size (AVSS) MPPT algorithm in the bulk stage, the time taken to get the battery to fully charge state becomes faster. The controller is able to control the duty cycle of the PWM by reducing it to $20 \%$ when the battery voltage is at $13.5 \mathrm{~V}$ (HVD) to protect the battery from overcharging. Besides that, the controller can disconnect the load connected to the system when the battery voltage dropped to 11.7V (LVD). However, the load is reconnected to the system once the battery voltage has achieved $12 \mathrm{~V}$ (LVR). The regulation power from the converter to the inverter has performed well and the switching relay is managed to be controlled.

\section{ACKNOWLEDGEMENTS}

The authors would like to acknowledge the Ministry of Education (FRGS Grant) FRGS/1/2018//TK1 0/UITM03/16 /for the financial support of this research project and Green Energy Research Centre (GERC) \& Solar Photovoltaic Energy Conversion Technology Research \& Application (SPECTRA), Universiti Teknologi MARA for the use of their equipment's in completing this research.

\section{REFERENCES}

[1] S. A. Jumaat, A. A. S. Ab Majid, M. N. Abdullah, N. H. Radzi, R. Hamdan, and S. Salimin, "Modeling of 120W Monocrystalline Photovoltaic Module Using MATLAB Simulink," Indonesian Journal of Electrical Engineering and Computer Science, vol. 11, no. 1, pp. 74-81, 2018.

[2] H. Chi, M. Tajuddin, N. Ghazali, A. Azmi, and M. Maaz, "Internet of things (IoT) based iv curve tracer for photovoltaic monitoring systems," Indonesian Journal of Electrical Engineering and Computer Science, vol. 13, no. 3, pp. 1022-1030, 2019.

[3] F. Nadeem, S. S. Hussain, P. K. Tiwari, A. K. Goswami, and T. S. Ustun, "Comparative review of energy storage systems, their roles, and impacts on future power systems," IEEE Access, vol. 7, pp. 4555-4585, 2018.

[4] G. A. M. Madrigal et al., "Fuzzy logic-based maximum power point tracking solar battery charge controller with backup stand-by AC generator," Indonesian Journal of Electrical Engineering and Computer Science, vol. 16, no. 1, pp. 136-146, 2019.

[5] N. Narayan et al., "Estimating battery lifetimes in Solar Home System design using a practical modelling methodology," Applied energy, vol. 228, pp. 1629-1639, 2018.

[6] X. D. G. Gumera, A. B. Caberos, S.-C. Huang, W.-R. Liou, and J.-C. Lin, "A Variable Duty Cycle Pulse Train Charger for Improving Lead-Acid Battery Performance," in 2017 Asian Conference on Energy, Power and Transportation Electrification (ACEPT), 2017: IEEE, pp. 1-4.

[7] M. Shoaib and V. Nagaraj, "Novel battery charging control system for batteries using on/off and PWM controllers for stand alone power systems," IOSR Journal of Electrical and Electronics Engineering (IOSR-JEEE), vol. 6, no. 3, pp. 44-52, 2013.

[8] M. Dakkak and A. Hasan, "A charge controller based on microcontroller in stand-alone photovoltaic systems," Energy Procedia, vol. 19, pp. 87-90, 2012.

[9] A. P. S. Negi, D. Bagai, and R. Mahajan, "A simple charge controller scheme based on PWM for solar standalone lighting systems," in Proceedings of the 4th international conference on Energy \& development, environment \& biomedicine, 2010: World Scientific and Engineering Academy and Society (WSEAS), pp. 34-37.

[10] G. Simbolotti, M. Taylor, and G. Tosato, "Solar Photovoltaics: Technology Brief," International Renewable Energy Agency, Abu Dhabi, United Arab Emirates, 2013.

[11] K. Ding, X. Bian, H. Liu, and T. Peng, "A MATLAB-simulink-based PV module model and its application under conditions of nonuniform irradiance," IEEE Transactions on Energy Conversion, vol. 27, no. 4, pp. 864-872, 2012.

[12] M. S. Hakim, F. Latif, M. I. Khan, and A. Basir, "Design and implementation of three-stage battery charger for lead-acid battery," in 2016 3rd International Conference on Electrical Engineering and Information Communication Technology (ICEEICT), 2016: IEEE, pp. 1-5.

[13] S. Armstrong, M. Glavin, and W. Hurley, "Comparison of battery charging algorithms for stand alone photovoltaic systems," in 2008 IEEE Power Electronics Specialists Conference, 2008: IEEE, pp. 1469-1475.

[14] V. Agarwal, K. Uthaichana, R. A. DeCarlo, and L. H. Tsoukalas, "Development and validation of a battery model useful for discharging and charging power control and lifetime estimation," IEEE Transactions on Energy Conversion, vol. 25, no. 3, pp. 821-835, 2010.

[15] M. Rokonuzzaman and M. Hossam-E-Haider, "Design and implementation of maximum power point tracking solar charge controller," in 2016 3rd International Conference on Electrical Engineering and Information Communication Technology (ICEEICT), 2016: IEEE, pp. 1-5.

[16] R. Dufo-López, J. S. Artal-Sevil, J. L. Bernal-Agustín, and J. A. Domínguez-Navarro, "Effect of the MPPT and SOC control of the charge controller in PV systems, " in 2015 17th European Conference on Power Electronics and Applications (EPE'15 ECCE-Europe), 2015: IEEE, pp. 1-7.

[17] S. B. S. Mora, E. A. L. Paipa, M. A. L. Serrano, and L. F. B. Márquez, "Performance comparison between PWM and MPPT charge controllers," Scientia et technica, vol. 24, no. 1, pp. 6-11, 2019. 
[18] H. Nademi, Z. Soghomonian, and L. Norum, "A robust predictive MPPT strategy: An enabler for improving the photovoltaic conversion source," in 2017 IEEE 6th International Conference on Renewable Energy Research and Applications (ICRERA), 2017: IEEE, pp. 1086-1091.

[19] B. Pakkiraiah and G. D. Sukumar, "Research survey on various MPPT performance issues to improve the solar PV system efliency," Journal of Solar Energy, vol. 2016, 2016.

[20] N. H. Baharudin, T. M. N. T. Mansur, F. A. Hamid, R. Ali, and M. I. Misrun, "Topologies of DC-DC converter in solar PV applications," Indonesian Journal of Electrical Engineering and Computer Science, vol. 8, no. 2, pp. 368374, 2017.

[21] T. Lueangamornsiri, K. Thongpull, K. Chalermyanont, and W. Wichakool, "Design and development of a standalone solar energy harvesting system by MPPT and quick battery charging," in 2016 13th International Conference on Electrical Engineering/Electronics, Computer, Telecommunications and Information Technology (ECTI-CON), 2016: IEEE, pp. 1-5.

[22] J. Zhang, G. He, and Q. Jiang, "Study of scheme for photovoltaic power system," in 2012 International Conference on Computational Problem-Solving (ICCP), 2012: IEEE, pp. 209-211.

[23] J. Pan, C. Wang, and F. Hong, "Research of photovoltaic charging system with maximum power point tracking," in 2009 9th International Conference on Electronic Measurement \& Instruments, 2009: IEEE, pp. 4-478-4-481.

[24] J. Jana, H. Samanta, K. D. Bhattacharya, and H. Saha, "Design and development of high efficiency five stage battery charge controller with improved MPPT performance for Solar PV Systems," International Journal of Renewable Energy Research, vol. 8, no. 2, pp. 941-953, 2018.

[25] S. Padhee, U. C. Pati, and K. Mahapatra, "Design of photovoltaic MPPT based charger for lead-acid batteries," in 2016 IEEE International Conference on Emerging Technologies and Innovative Business Practices for the Transformation of Societies (EmergiTech), 2016: IEEE, pp. 351-356.

[26] B. S. Manju, R. Ramaprabha, and B. Mathur, "Modelling and control of standalone solar photovoltaic charging system," in 2011 International Conference on Emerging Trends in Electrical and Computer Technology, 2011: IEEE, pp. 78-81.

[27] Z. Mehmood, Y. Bilal, M. Bashir, and A. Asghar, "Performance analysis of MPPT charge controller with single and series/parallel connected PV panels," in 2016 International Conference on Intelligent Systems Engineering (ICISE), 2016: IEEE, pp. 278-282.

[28] N. H. Abdul Rahman et al., "Auto-Scaling Variable Step Size Incremental Conductance Maximum Power Tracking Control Algorithm for Photovoltaic System " International Journal of Engineering \& Technology, vol. 7, pp. 165169, 2018.

\section{BIOGRAPHIES OF AUTHORS}

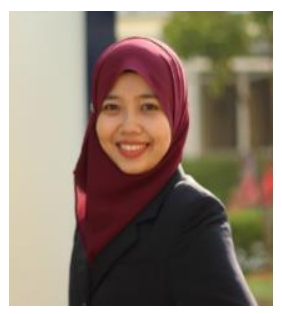

Noor Hasliza Abdul Rahman received her B. Eng. (Hons) in electrical engineering from Universiti Putra Malaysia in 2006 and M.Sc in Electrical Engineering from at Universiti Teknologi MARA in 2014. Since 2014, she has been a lecturer in Department of Power, Faculty of Electrical Engineering, Universiti Teknologi MARA, Cawangan Johor Kampus Pasir Gudang. Her field of interest is photovoltaics and renewable energy technologies.

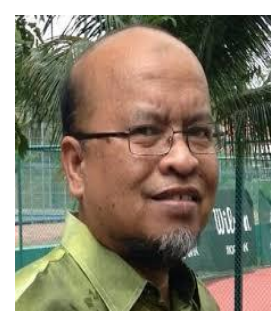

Ahmad Maliki Omar obtained his B. Eng. (Hons) in electrical engineering from University of Malaya, M.Sc. in power electronics from Loughborough University, UK, Ph.D. in power electronics from University of Malaya. Currently he lectures at Universiti Teknologi MARA, Shah Alam, as an Associate Professor of Electrical Engineering Department. His main research interests are in Power Electronic Converters, Dedicated Controller, and Automation. Also, areas of interest in the inverter design, PV hybrid monitoring system and sizing of PV systems

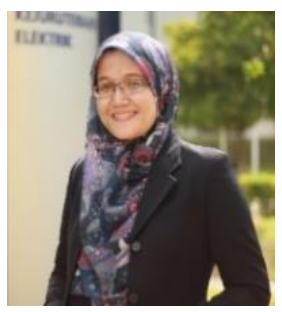

Nur Iqtiyani Ilham obtained Bachelor of Electrical Engineering (Hons) in 2008 from Universiti Kebangsaan Malaysia and University of Duisburg Essen, Germany, MSc in Power in 2014 from University of Malaya, Malaysia. In 2014, She has joined UiTM Pasir Gudang Campus as a lecturer at the Faculty of Electrical Engineering, Department of Electrical Power. Her research interest is more towards Smart Grid Technologies, Energy Policy and Artificial Intelligence. 


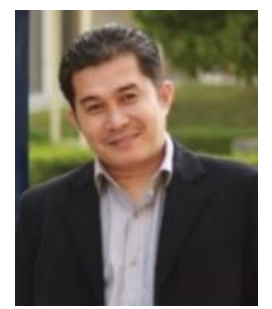

Ezril Hisham Bin Mat Saat obtained his B. Eng. (Hons) in electrical engineering from University Teknologi Malaysia, M.Sc. in electrical engineering from Universiti Putra Malaysia. Currently he lectures at Universiti Teknologi MARA, Cawangan Johor Kampus Pasir Gudang, as a senior lecturer in Electrical Engineering Department. His main research interests are in Computer Engineering, Robotics, Artificial Intelligent, and IoT field.

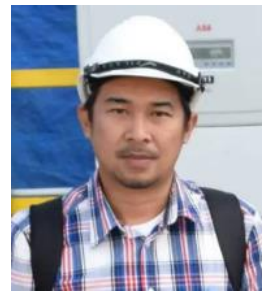

Mohamad Zhafran Hussin obtained his PhD degree in the field of Photovoltaics at Universiti Teknologi MARA (UiTM). His main research interest focuses on solar photovoltaics and wind turbines, also interest in other renewable energy technologies.

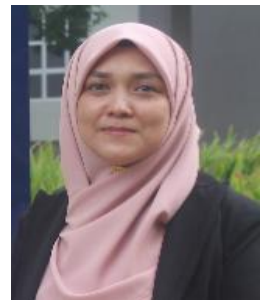

Yusrina Yusof obtained B. Sc in Electrical Engineering (Hons) in 1999 from Widener University, Chester, Philadelphia, USA and Master of Electrical Engineering (Power) in 2017 from Universiti Teknologi Malaysia. In 2014, she has joined UiTM Pasir Gudang Campus as a lecturer at the Faculty of Electrical Engineering, Department of Electronics. Her research interest is more towards Power Quality and Artificial Intelligence. 